\title{
WHAT SHOULD THE VOTER KNOW? EPISTEMIC TRUST IN DEMOCRACY
}

\author{
Michael BAURMANN \\ Heinrich-Heine-Universität Düsseldorf \\ Geoffrey BRENNAN \\ Australian National University / Duke University / \\ The University of North Carolina at Chapel Hill
}

\section{Summary}

Alvin Goldman develops the concept of "core voter knowledge" to capture the kind of knowledge that voters need to have in order that democracy function successfully. As democracy is supposed to promote the people's goals, core voter knowledge must, according to Goldman, first and foremost answer the question which electoral candidate would successfully perform in achieving that voter's ends. In our paper we challenge this concept of core voter knowledge from different angles. We analyse the dimensions of political trustworthiness and their relevance for the voter; we contrast two alternative orientations that the voter might take-an "outcome-orientation" and a "process-orientation"; and we discuss how an expressive account of voting behaviour would shift the focus in regard to the content of voter knowledge. Finally, we discuss some varieties of epistemic trust and their relevance for the availability, acquisition and dissemination of voter knowledge in a democracy.

\section{A veritistic theory of voter knowledge}

Alvin Goldman's stimulating and multifaceted book Knowledge in a Social World explores the possibilities by which human knowledge can be increased via social institutions and processes. He calls this normative project "veritism": "Under veritism we are asked to select the social practices that would best advance the cause of knowledge." (Goldman 1999, 79) One of the domains in which Goldman tries to find answers to this question is democracy. His starting point is the suggestion that "the successful functioning of democracy, at least representative democracy, depends on the acquisition 
of certain types of knowledge by particular actors or role-players". As the essence of democracy for Goldman is rule of the people for the people by means of voting, "voter's knowledge is the first place to look for forms of knowledge that are central to democracy" (315). Following Christiano, Goldman interprets having a vote in a certain group as having a certain type of resource that enables one to influence that group's collective decisions. What then is the role that knowledge ought to play from this point of view in a well-functioning democracy?

Whatever this role may be, the diagnosis by political scientists of the state of affairs seems to be clear: "ordinary American citizens have a minimal, even abysmal, knowledge of textbook facts about the structure of American government, the identity of their elected officials, and fundamental facts about contemporaneous foreign policy" (317). The picture for German voters may not be as grim as for Americans, but surely is far from the ideal of completely informed rational deciders who consider all potentially relevant facts before casting their vote.

However, Goldman rightly argues that we cannot evaluate the average voter's knowledge adequately and think of possible remedies if we do not have a firmly grounded idea about the kind and depth of knowledge a well-functioning democracy actually demands: "What kinds of knowledge (or information) is it essential that voters should have?" (320) We have to specify the kinds of facts that are critically important for voters to have before we can think in the spirit of veritism about social practices/ institutions that would best advance the cause of relevant knowledge in the domain of democracy. Accordingly, Goldman's first task is to specify "core voter knowledge", a type of knowledge that voters in a representative democracy should have if the democracy is to function optimally. (320)

Goldman develops such a specification on the basis of a particular view about the aim of representative democracy: according to this view, democracy is supposed to promote the citizens' goals or ends and in a representative democracy, therefore, it is the duty of elected representatives to execute the best political means towards the achievement of these goals or ends. The citizenry itself will normally be some composite of egoistic and altruistic types. But, whatever each citizen's ends are: "it is assumed that he or she votes for electoral candidates on the basis of his or her estimate of how well the competing candidates would perform in achieving that voter's ends." (321) For the sake of simplicity, Goldman ignores the problem of whether it is rational to vote given the low probability that a single vote will swing the election-an omission to which we will want to return. 
The voter's ends are operationalised by Goldman as preference orderings over outcome sets. "Outcome sets" are the combination of outcomes that have resulted from a certain politician being elected and holding office for a given term. The elements of an outcome set-for example, the level of employment, the cost of living, the crime rate, the quality of the environment - are directly valued by the voters so that, for each pair of outcome sets, a voter prefers one to the other or is indifferent between them. Consequently, if the result of the performance of a politician $C$ is an outcome set $O_{1}$ which a voter $V$ rank-orders above an outcome set $O_{2}$ which another politician $C^{*}$ would have produced as an elected official, then $C$ was a better official from the point of view of voter $V$ than $C^{*}$ would have been. Of course, the holder of an office is constrained by all sorts of restrictions; and the outcomes that result from that holder's term of office are a function of numerous factors. But as long as there are differences between the two outcome sets associated with any two candidates and as long as a given voter is not indifferent between these outcome sets, which one is elected should make a genuine difference to the voter.

Based on this analysis, Goldman states the "core voter question" that a voter needs to ponder in deciding how to vote: "Which of the two candidates, $C$ or $C^{\prime}$, would, if elected, produce a better outcome set from my point of view?" (323) If a voter believes the true answer to this question, he has "core knowledge" and "it is reasonable to assume" that his vote will accord with his core belief: if he believes that $C$ would produce a better outcome set than $C^{\prime}$, then he will vote for $C$ (324).

According to Goldman, democracy is successful when the electorate has full core knowledge, that is when every voter knows the true answer to his or her core question. Full core knowledge, under majority rule in a two-candidate election, guarantees that a majority of citizens get their more preferred outcome set; high levels of core knowledge at least can make such a result highly probable. This, says Goldman, "is a good or successful result from the standpoint of democracy's goals" (326). The greater the core knowledge, the better for democracy: "core voter knowledge is critically valuable for the realization of democratic ends." (329)

The concept of core voter knowledge serves Goldman as a decisive criterion for the importance or unimportance of other types of voter knowledge- for example knowledge about the candidates' past records, their policy platforms and promises, their ideologies, their personalities, skills, and political competences, their debts to interest groups, and so forth. For Goldman, the importance of all these other forms of knowledge 
lies exclusively in their impact on the voter's core opinion $(325,329)$. Such knowledge is valuable if it contributes to core voter knowledge, and irrelevant otherwise. Similarly, social practices and policies that influence the circulation of political information and disinformation among voters should be assessed by their conduciveness to core voter knowledge.

How can we, in realizing the veritistic program, improve core information for the voter and by these means improve core voter knowledge? Which facts and patterns exist in current democracies that are detrimental to adequate voter knowledge and what could be the remedies?

In regard to the information-seeking practices of voters themselves, Goldman discusses two problems which both have to do with the hypothesized shortcuts voters actually engage in. One is a tendency to listen to like-minded sources and to ignore conflicting sources of political information. This problem might be ameliorated, Goldman maintains, by implementing Fishkin's concept for a "national caucus" (Fishkin, 1991). The idea is to assemble a representative sample of the citizenry for several days and let them debate political issues in depth with the candidates. The preferences and opinions of the delegates would then be polled and communicated to the public. In this way, better grounded opinions might influence the assessment of candidates by the other citizens.

A second shortcut that voters are supposed to take in making their decision is "retrospective voting". According to this hypothesis, voters simplify their decision between an incumbent and an opponent by judging how well the incumbent has performed during the current term in office and how well off voters are as a result. Goldman contends that it is obvious that the retrospective voting shortcut can be seriously misleading as a guideline to answering the core question. Even if the incumbent has performed well during the past term of office, the challenger might do even better the next time; and if the incumbent performed badly, the opponent might do even worse. Moreover, the retrospective approach does not adequately consider the importance of contextual factors for good or bad results of policies; and in any case, is applicable only to chief executives since politicians in other positions can hardly be held responsible for the outcomes of politics in a certain term. Despite the perceived shortcomings of retrospective voting practices, however, Goldman does not recommend any special remedies.

Goldman then turns to the behaviour of candidates and elected officials and the parties that endorse them. He takes the dominant aim of politicians and parties to be electoral victory, and argues that contenders will have strong incentives to communicate to the voters whatever they 
think will contribute to that victory whether or not the statements are true or accurate. Goldman mentions several measures that might counteract these incentives: systematic coverage of political advertisements, "in which reporters examine campaign ads for truthfulness and realism" (338); the application of laws that require candidates to disclose campaign contributions and expenditures and reveal who is paying for commercials and airtime; the "Freedom of Information Act" that allows citizens access to information from federal agencies; and a system of proportional representation that encourages an extensive articulation of party platforms and programmes and thus a spread of detailed information for voters (as prevails specifically in Germany).

Finally, Goldman turns to the pivotal role of the press in political information processing. "Ideally", Goldman argues, "the press should comprise a set of experts who would report, interpret, and explain political events in a way that serves the veritistic interests of voters, especially their interest in core voter knowledge. Since ordinary citizens cannot be expected to acquire such knowledge entirely on their own, and since successful democracy depends on their acquiring such knowledge, the responsibility of promoting and facilitating this knowledge naturally falls to the press" (340). Goldman envisages two barriers to an adequate fulfilment of this role by the press. The first is the profit-orientation of commercial media, which results in striving for popularity by the publication of superficial and plainly entertaining stories. Goldman especially criticizes the tendency to present politics in a "strategic game schema" that emphasizes the competitive and horserace-like nature of politics, instead of interpreting election-rated information within a "policy schema" more focused on citizen interests.

The second problem Goldman identifies is the insufficient professional training of journalists and reporters. Currently, journalists are not required to have any systematic knowledge of history, the liberal arts, natural sciences, or sociological and economic analysis. Therefore, they are not equipped to fulfil the role of "public explainers" who put the events of the day in context. Goldman is not optimistic about prospects for improvement of the press: certainly in the case of the commercial press he thinks it unrealistic to set expectations very high. Hopes for improvements in the media in doing a responsible and commendable job from the veritistic perspective, Goldman confines to publicly supported radio and television. 


\section{Discussion}

\subsection{Political trust}

In what follows, our object is to broaden and complement Goldman's treatment rather than to criticise and revise it. In pursuing that objective, it will be useful to frame the analysis of the role of knowledge in a representative democracy in a slightly different way. We accept Goldman's point of departure that democracy is supposed to promote the citizens' goals or ends; and that in a representative democracy, therefore, it is desirable that elected representatives try to achieve these goals or ends as best they can. We can conclude from this elementary characterization that the successful functioning of a representative democracy depends on having representatives that are trustworthy - that they are motivated to pursue citizens' goals/ends; have the ability to discern what these goals/ ends are; and the capacity to achieve those goals/ends on the citizens' behalf.

To use the term trustworthiness to characterize the essential feature of a democratic representative refers to the fact that the relation between citizens and their representatives exhibits a strategic structure that can be characterized as a "trust-problem" (Lahno 2002). A trust-problem is embodied in situations in which one person, as the "trustor", makes himself vulnerable to another person, the "trustee", by an act of "trust-giving". That a trustor makes himself vulnerable to a trustee signifies that the trustee can harm the trustor by his actions. The incentive for the trustor to take this risk lies in the fact that trust-fulfilment by the trustee would improve the situation of the trustor compared with a situation in which the trustor fails to make himself vulnerable to the potential trustee. Trustproblems, so understood, are a ubiquitous feature of human co-operation and coordination; and their structure is responsible for the fundamental dilemmatic character of social order because incentives to abuse trust can prevent a mutual advantageous trust-relationship and harm the interests of both parties.

The relation between citizens and their democratic representatives embodies a trust-problem because (a) in assigning political decision-making power to their representatives, the citizens make important aspects of their well-being dependent on the acts of their representatives, and in this sense make themselves vulnerable to them; (b) their incentive to do so rests on the hope that a delegation of political power to reliable representatives 
can realize their interests better than without such a delegation; (c) the citizens express this hope in a variety of ways, but most centrally by casting their vote for candidates in democratic elections.

We have said that a "trustworthy" representative both tries to promote the represented people's goals or ends, and is also able to do so. We can be a bit more specific, by enumerating at least four factors that are crucial in this respect (Baurmann 2007a):

1. Competence. To successfully promote the goals or ends of represented citizens, a politician in a democracy must possess appropriate intellectual and practical abilities. These abilities rest on a combination of political skills such as assertiveness, communicative competence, rhetorical talent, bargaining ability, strategic planning, visionary thinking, and empathy towards the electorate.

2. Resources. To be successful in politics also requires the factual means and opportunities to achieve one's objectives during a term in office. If a brilliant politician lacks the resources and political power to deploy his personal qualities successfully, she will not be able to realize her projects and wishes. Obviously, in a democracy, politicians can be constrained by manifold restrictions that hinder them from effectively influencing political decisions and implementing their plans.

3. Incentives. Material and immaterial benefits and costs, formal and informal rewards and sanctions, institutional checks and balances, social recognition and contempt can motivate officials to utilize their resources to promote the goals and interests of their electorate. But discretionary power and extrinsic incentives can also tempt politicians to behave opportunistically, to underachieve or to neglect their duties, to misuse their resources and political power for private goals and interests and/or to manipulate or deceive the citizens.

4. Dispositions. Emotional bonds of solidarity, sympathy and benevolence; the internalisation of social values and norms; moral virtue and personal integrity-these can all motivate representatives to act in the well-being of the represented, for its own sake. Equally, emotional aversion and hatred; the internalisation of deviant values and norms; moral vices and malice: are potential reasons to misuse power and to harm the interests of the citizenry. Dispositions of intrinsic motivation are of special importance because they can trump extrinsic incentives-in both directions. Extrinsic incentives 
to behave opportunistically could be overridden by intrinsic motivation to behave in accordance with moral principles and ideals, just as extrinsic incentives which reward obliging behaviour could become invalidated by emotional repugnance, personal weakness and mischievous aims.

What this list suggests is that the overall trustworthiness of politicians is dependent on a complex set of interconnected conditions and factors. Accordingly, it will not be an especially easy task to assess the trustworthiness of an official or a candidate for office. What should the voter know if he wants to form a considered judgement about the reliability and qualifications of a politician? If we agree with Goldman that citizens vote for competing electoral candidates on the basis of their estimate as to how well a candidate will perform in achieving their ends, and that these ends are adequately operationalised as preference orderings over outcome sets, then the demand for knowledge would indeed include the full range: a voter would then have to have knowledge of the competence and political skills of candidates, the resources and opportunities these candidates will probably have access to during their time in office, the hurdles they will face, the incentives that will have an impact on their decisions and performance, and last but not least the personal dispositions, which will shape their intrinsic motivation in face of the temptations of power.

In this case the "core voter knowledge" would include a wide range of context-specific sub-types of knowledge and the sources and the bases of the relevant information accordingly differentiated and diverse. To judge the professional competence and political skills of candidates would require knowing their track records in different kinds of political situations; to estimate their resources and opportunities would demand a well-founded assessment of their future position, for example in their party or in a government and a prediction about the composition of government and parliament, and a prognosis of the possible development of the general political situation. To estimate the incentives that will have an impact on their political acting requires knowledge ranging from the overall institutional structure of a political system and political culture, to the influence of interest groups and the general stability of the political process in a country. To judge personal dispositions and individual virtues and vices of a person presupposes knowledge of a quite different sort: facts about personality and past behaviour, even of a private sort. 
Depending on the respective type and source of knowledge, the voter is confronted with different problems and obstacles-and risks. Past record may not be a good source of knowledge about comparative advantages or disadvantages of competing candidates in regard to successfully realizing certain outcomes when in office. But past records serve much better if they are utilized to get information about the virtues and vices of different persons. Commercial media may not distribute qualified knowledge from political experts and "public explainers" or communicate the intricate details of candidates' political programmes. But they are likely to fare better in circulating information about the personal characteristics of politicians. In this sense, a bias towards the "strategic game schema" and a proclivity for reporting conflicts and scandals may not be entirely dysfunctional. Knowledge about incentives would presuppose knowledge about institutions, political culture and general facts in a society, and sources in this respect will range from "political education" to gossip and hearsay.

\subsection{Outcome vs. process}

Goldman concretizes the general presumption that democracy should promote the people's goals or ends by conceiving these goals or ends as preference orderings over outcome sets. For the moment let us accept this broadly instrumental picture. Our question is whether, given this view, and given the inevitable difficulties of predicting the future course of events, it makes sense for voters to focus their evaluations on policies or on candidate qualities.

Suppose the voter is essentially egoistic: he seeks policy outcomes that will serve his personal interests. Of course, his preferences over specific outcomes cannot be unconditional. He wants to have clean water and clean air, but only if the costs of a healthy environment are not too large. He does not want his country to become engaged in a costly war, but will not want the government just to surrender to a foreign aggressor. He would like to have low taxes, but only if low tax levels do not risk costly social turmoil associated with a sense of injustice by the socially disadvantaged. The problem here is that the relevant "conditions" might change: the disadvantaged may become restive; external relations may become more tense; perceived environmental costs may increase or fall.

Therefore, a self-interested citizen expects from politics that it will produce a state of affairs in which not only certain prefixed and enumerable outcomes are realized, but in which all his ends, goals and interests are 
considered as inclusively and well-balanced as possible so that the overall result is maximized from his point of view. But at the beginning of a term, no voter will be able to foresee how things will work out or what policies are required to best promote his or her interest. Even if voters did know that a candidate would indeed produce a certain outcome set, they cannot be sure ex ante how they would evaluate this outcome set in the future because this evaluation will depend on other circumstances that may have altered in the interim.

From this it follows that the "egoistic" voter must switch her attention from "outcome" to "process". As she cannot know at the beginning of a term what kind of outcome would serve her interests best at the end or during the coming term, her chief concern must be that the procedure by which future collective decisions are reached is such that her personal interests are considered and weighed as strongly as possible - so that the outcome set, unknown and not yet specifiable, will then be optimal according to her preferences.

Similar conclusions can be made in regard to an "altruistic" voter. Let's suppose that the dominant preference of an "altruistic" voter is that politics produces "just" outcomes which include the interests of everyone. But there are at least two ways to ascertain the justness of an outcome. The first one is to apply a "patterned" or "end-state" view of justice. That means that the justness of a given state of affairs is measured against criteria that evaluate directly the existing facts: whether, for example, a certain distribution of goods and burdens maximizes the utility of the greatest number, promotes the interests of the most disadvantaged or complies with egalitarian yardsticks-irrespective of the history of its development or the conditions of its origination. In this case the "altruistic" voter faces the same difficulty as her purely egoistic counterpart. Because of inevitably limited knowledge about the future she can not specify in advance a concrete outcome set which will at the end of a term satisfy her criteria for justice. Therefore, she too is forced to switch her attention away from the outcome set to the process of politics and to ask what qualities a process of collective decision-making must have to promote outcomes with "patterns" that, in the end, can count as "just".

Of course, the focus on processes will follow directly if justice is itself defined in process terms (as it is in certain entitlement theories of justice and procedural accounts of democracy).

It seems then that, independent of the precise details of voter motivation, a shift from outcome-orientation to process-orientation in the 
attitudes of voters will be required. We can leave it open here whether this shift will be complete or whether there will a kind of mixture of outcome- and process-orientation. What is central here are the consequences such a shift would have for core voter knowledge and therefore for the veritistic program. The core question for the voter would be no longer "which is the best policy package" (whether "best" is understood as "best for me" or "best" in some more normative sense) but rather "which of the candidates would, if elected, be likely to choose a better outcome set from my point of view?" What qualities must a representative have from this perspective, and what kind of core voter knowledge is hence necessary?

For an "egoistic" voter the main concern will be that his interests are accounted for as extensive as possible in the political process and in political decisions. Such a voter will have to discern the extent to which alternative candidates have internalised their particular interests. For an "altruistic" voter the main concern will be that the political process produces "just" outcomes which include everyone's interest. From this it follows, at least on the "straight-forward" view, that politicians in office should consider the interests of everyone as thoroughly and in as balanced a manner as possible-again, whatever their concrete role and the extent of their power may be.

More sophisticated views may induce "egoistic" voters to assume that their personal interests would be better served if their representatives observed the limitation imposed by appropriate moral or political principles when in office and did not merely act as ruthless executors of their ideology. Conversely, an "altruistic" voter might think that the general welfare is better achieved if representatives act as advocates of their constituents' interests and do not presume a vocation to act for the common good, relying on abstract properties of the process to generate the desired overall pattern of outcomes. And several positions between these extremes are conceivable.

However, these complications are not strictly relevant to the point we wish to make-which is that process-oriented voters in a representative democracy, whatever their motives, will be primarily interested in the characteristics of their empowered agents in their political roles. The "trustworthiness" of a candidate will be depend in part on the extent to which he bases his decisions on the "right" reasons from the point of view of the voter. Of, course, the other dimensions of trustworthiness will not lose their relevance. The competence of a politician, his resources to influence 
outcomes of the political process, the incentives he faces and his personal dispositions still play their role in the overall judgement of the voter. But an important difference with the outcome-oriented voter remains: process-oriented voters will not make their judgement of "trustworthiness" contingent on the ability of a politician to produce a certain and specified outcome set.

This different focus has some significant consequences within the veritistic perspective. Goldman is very sceptical about the veritistic value of "retrospective voting" where voters are supposed to simplify their decision problem by asking how the incumbent has performed during his term in office. Goldman is right in his scepticism if retrospective voting is tantamount to answering the question as to how well-off the voter is as a result of the incumbent's current tenure. The prospect for retrospective voting brightens, though, if the voter does not focus upon outcomes but upon the behaviour of an incumbent during his term in office and the reasons on which he based his decisions. Even if the outcome were satisfactory but for the "wrong" reasons, the voter could well conclude that prospects for the future are better if the "right" reasons had determined the decisions of the incumbent. And, in contrast to the outcome-orientation, if voters are able to recognize the decision behaviour of officials, they do have not to estimate the influence of contextual factors to judge the "true" impact of the politician.

Furthermore, process-orientation has the additional advantage that by retrospective voting the voter also has a better chance to judge the qualities of the challenger of an incumbent. With an outcome-oriented approach this is difficult because it is not easy to get evidence of the possible performance of a challenger with regard to producing certain future outcomes. But it is much easier to get evidence for the decision calculus of a challenger-the calculus that she will apply in future situations. There are many different contexts in which a challenger can convincingly reveal the reasons on which she will base her political decisions if she is elected to office. And her past performance in a different context can be telling in this regard-even when her relevant political experience is very thin.

All in all, there seem to be better chances for process-oriented voters to acquire core voter knowledge than for purely outcome-oriented voters. Their focus will be on the personal characteristics and intrinsic motivations of candidates - features which are revealed by the facts about the candidates' past and current behaviour and performance, not on the risky and 
complicated prognosis what kind of outcome they will produce in a future term when elected in office. In short: voters' attention will be rationally directed more towards candidates than towards policies.

\subsection{Instrumental vs. expressive voting}

Goldman's concept of core voter knowledge could also be challenged in a more fundamental way. He follows Christiano in his interpretation that having a vote is to have a certain type of resource to influence collective decisions. Consequently, voters will use this resource to vote for electoral candidates on the basis of their estimation of how well candidates would perform in achieving the voter's ends. From this point of view the vote is an instrument by which the voters try to intervene in the world and to change the course of things in a way which best serves their preferences. This approach has a long history in the Rational Choice and Public Choice tradition.

But as an interpretation of what truly rational voting behaviour would require, this 'instrumental' view of voting is deeply problematic-for the simple reason that the single voter in a fairly large group does not determine the result of an election, except in very special circumstances. Unlike decisions in the market place, for example, the voter does not actually choose between political options. The opportunity cost of V's voting for candidate $\mathrm{A}$ is not candidate $\mathrm{B}$ forgone-just a vote for $\mathrm{B}$ forgone. So the idea of agents directly choosing policy packages (or the social outcomes that those packages produce) is defective. In other places and collaborations (see Brennan and Lomasky 1993 and Brennan and Hamlin 2000) one of us has developed an alternative "expressive" view of voting behaviour according to which the act of voting is to be seen more as a speechact by which a voter wants to express his support for a candidate or his approval for a policy and in which his instrumental interests will play only a minor or indirect role. Voting is to be thought of more as a matter of cheering at a football match - of "showing support"-than of choosing an assets portfolio. For example, on this view, voters can rationally vote for candidates even when the outcome of the election is determined (as Californian voters have been known to do in US Presidential elections, when the result has already been known). More to the point, the kinds of considerations that weigh in voter deliberation are connected to the factors that induce people to "cheer" rather than to the factors that might induce them to choose. 
To specify what such considerations are is no small task. But things like the personal characteristics of candidates (charisma, charm, rhetorical appeal, even good looks), or the moral attributes of the candidate and/or the policies she is associated with seem more likely contenders in most cases than the individual voter's interests. Just as Rawls' veil of ignorance serves to background individual interests, so the "veil of insignificance" that characterises the individual voter's actions will rationally reduce the role of self-interest and augment the role of directly "expressive" and symbolic factors. Of course, expressive voting does not exclude voting for the candidate who, in a voter's estimation, will serve that voter's ends best. But any voter who does this cannot plausibly do it instrumentally, to influence the collective decision in the "right" direction; she must vote that way because she wants to identify herself with a particular position and to express her affirmation and appreciation for a candidate who takes that position.

If we accept that the theory of expressive voting captures relevant aspects of voting in a democracy, then we have to adapt the concept of core voter knowledge accordingly. The main consequence will be that core voter knowledge no longer has a specified substance. The reason for this is that it is not prefixed what individual voters want to express by their voting in a democratic election. If voters want to express their approval of a candidate, because they think that that candidate will probably produce the best outcome set from their point of view, then the core voter knowledge as Goldman has specified it will remain the same.

But voters in a democracy can and in fact do express quite different attitudes, beliefs and values by their votes. They can express by their vote that they very much appreciate an important singular outcome of a recent policy, without necessarily assuming that the incumbent will also in future be the one who will produce the best outcomes. For example, many German voters seem to have expressed their approval of Chancellor Schröder's decision not to take part in the Iraq war, quite apart from his perceived qualities as a future leader. In the same way, voters can use their vote to express their disapproval with a singular outcome-for example, that the incumbent has not kept his election pledge in a certain question. Voters can express a general disenchantment with politics or politicians - for example by casting their vote for a radical party-without necessarily hoping that this party will come into power. And voters may express their esteem for a politician who has acted especially admirably in a certain regard even if they do not assume that he is adept at producing overall good outcomes. 
An example could be the respect Chancellor Willy Brandt enjoyed at the ballot box after his reconciliation politics.

Of course, this list of possibilities just is a list of possibilities. Unlike the instrumental account of voting, the expressive account is somewhat open-ended and the limits imposed on voter attitudes extremely loose. All of these possibilities are, however, entirely consistent with rationality on the voter's part. There is of course systematic evidence that shows-for example - that a candidate's vote share, other things equal, is significantly increased by his good looks (Leigh and Susilo 2008). But the important point here is that the qualities that induce "cheering" (and "booing") are as likely to be connected with the perceived qualities of the candidate as the policies that candidate promotes - and even in policy assessment are unlikely to track voters' prudential interests in any close way.

From the perspective of expressive voting the often bemoaned "personalization" of politics makes perfect sense. The core voter knowledge would therefore be a quite intangible and fluent phenomenon and the core voter question consequentially would be highly time and context dependent.

What are the implications for the veritistic agenda? Certainly not that the supply of reliable information and knowledge about politics and politicians should be reduced. But we have to face the fact that the nature of the political information demanded is likely to show a substantial variation across voters, and for any one voter across time. Core voter knowledge for voter $V$ is not the same as for voter $V^{*}$ and for voter $W$ at time $\mathrm{t}_{1}$ not the same as at time $t_{2}$. Therefore, we have to put a question mark behind the possible veritistic ideal that all voters should possess a uniform and maximal knowledge about politics and politicians all the time.

The expressive voting account has some similarities with the problem of "rational ignorance". The rational ignorance arguments emphasise the lack of incentive to acquire relevant political knowledge given the fact that no rational voter can expect the probability of his being determinative in an election to be other than very tiny. The expressive voting arguments take the same point of departure but the conclusions made are rather different. Many "expressive" voters may be quite well-informed about those aspects of politics that engage their expressive concerns-much in the same way as keen football fans often know a huge amount about their team members and their records and about football statistics in general (none of which information, incidentally, has any prudential relevance!). Even so, "rational ignorance" considerations still lurk in the undergrowth: nothing in the expressive account denies that many voters will know very 
little about the objects of their vote or the issues at stake in casting that vote one way or the other.

And we think that Goldman is rather too quick to set aside the "rational ignorance" challenge. In any "veritistic" enterprise in the democratic context, what incentive voters will have to acquire whatever information is deemed relevant has to be a central question. The rational ignorance challenge is too basic to be set aside in the interests of simplification. As we have indicated, the expressive account of voting offers a reasoned account not just of the levels of turnout (why people will rationally vote in the numbers that they do) but also of why they may acquire information about the aspects that are relevant to electoral choices.

However, if the expressive voting theory is correct-whether as a supplement to an instrumental theory of voting or a substitute for it and whether applicable to all voters or just a subset-there are important follow-up questions for a theory of democratic information. One of the most salient is the question of how democratic elections can be made to reliably generate political outcomes that will best serve the ends or goals of the citizens. This question takes us well beyond the scope of this paper. But it can hardly be pretended that it is an unimportant one; or that it does not bear critically on the kind of information that it is plausible that democratic citizens will have reason to acquire.

\subsection{Epistemic trust in democracy}

From a veritistic perspective, societal, political and legal institutions of public knowledge production and distribution matter a great deal — both in general, and in relation to politically relevant knowledge in particular. These institutions determine to a large extent whether the production and distribution of knowledge is efficient, whether there is control of and competition between different sources, whether there is freedom of speech and information, whether experts acquire adequate competence and sufficient resources and have incentives to distribute reliable information and useful knowledge. However, what is true for other kind of institutions is also true for epistemic institutions: institutions are always embedded in a social and cultural environment that is a crucial factor for the efficiency and the functioning of these institutions. "Soft" factors like social norms and cultural values, history and tradition are important in determining whether institutions can actually realize the aims for which they were designed or on the basis of which those institutions are justified 
(Baurmann 2007b). Both the institutional framework of a society and the social embeddedness of this framework and its impact are central to the project of realising veristic ideals.

In the context of the present discussion we want to investigate a factor that seems to us of special importance for the veritistic agenda in general and in regard to the availability of knowledge in a democracy in particular. This is the role of trust in the acquisition, validation and utilisation of information (Hardwig 1991, Govier 1997). This role of trust is not so much a matter of the relation between voters and politicians as such; it deals rather with the role trust plays in relations among citizens within the epistemic division of labour, specifically when they want to gather information about the trustworthiness and other relevant personal characteristics of officials and candidates.

The relation between institutions and trust is generally intricate. On the one hand, well-designed and well-ordered institutions in politics, law or economy can create and nurture trust. On the other hand, without trust even well-designed and well-ordered institutions can hardly function properly and produce the results that might be hoped for them. The same is true for institutions that are planned to serve veritistic purposes in a democracy. Where exactly does trust come into play when we are dealing with the ways in which voters can gain relevant knowledge?

In the first place, whatever kind and range of knowledge is needed for voters, it seems to be obvious that it cannot be acquired by individual voters entirely on their own. Voters will be dependent on testimony, on information and knowledge from other people and sources, in order to accumulate the necessary knowledge (Coady 1992, Matilal and Chakrabarti 1994, Schmitt 1994) - a fact that Goldman himself mentions when he discusses the pivotal function of the press. This dependence on external sources exists not only because individuals have a resource-problem and simply do not have the time or the opportunity to gather and validate all relevant information about politics and politicians entirely individually. Average citizens also have a competence-problem. If, for example, they want to know something about the typical incentives politicians face in office or whether a certain policy is an appropriate instrument to bring down unemployment or to limit household deficits, they will need expert assistance. Goldman is right to emphasise the role of professional experts and "public explainers" who can elucidate political issues for the political laymen.

From this follows that to identify trustworthy politicians, voters must identify trustworthy informants who can provide them with the kind of 
knowledge they need. Not surprisingly, the requirements for being a trustworthy informant are much the same as the requirements for being a trustworthy representative: a trustworthy informant must be competent, and he must possess appropriate cognitive and intellectual abilities as well as sufficient external resources to identify the relevant information, and he must be disposed to pass on that information accurately. Informants' motivations to exploit their cognitive potential, to utilize their connections to discover useful information and to transmit their knowledge to the recipients depend both on informants' incentives and dispositions; but incentives and dispositions can also tempt informants to behave opportunistically, to underachieve and/or to misuse their resources and to deceive recipients with wrong, misleading or useless information.

Of course, different information transfer settings demand different levels of trust. To judge the reliability and sincerity of information about the time of day does not require deep insights into the special competence, incentives or motivations of the informer (Fricker 1994). But as a typical voter, to judge the special competence of political experts and "public explainers" is quite another task. Two questions, then. First, what epistemic sources are relevant for voters to gain relevant knowledge? And second, what is at stake in assessing the reliability and trustworthiness of such sources?

\section{Trust in epistemic authority}

As already noted, the individual voter does not only have a resource-problem to accumulate all relevant information about politics and politicians, but also a competence-problem. That means that the average voter is dependent-over a more or less wide range-on additional information and knowledge of political experts and authorities to form a well-founded opinion about the trustworthiness of politicians in general and in the concrete case. He may also be looking for advice and orientation from opinion leaders and spokespeople who are able to condense and articulate the interests and hopes of a group or community.

Therefore, as Goldman already points out, from a veritistic perspective it is highly important that, in a democracy, political experts and specialists are available who are professionally competent, possess personal integrity and can explain political complexities and problems to the public. But to have trustworthy experts and analysts is only half the battle. They must also be recognised as trustworthy — that is, actually trusted - by the public so that the "truths" they reveal are believed and distributed. To accomplish 
this and to promote and secure trust in experts and authorities in all fairly developed societies - in politics as well as in other areas-numerous variants of rules and criteria are employed to assign and identify the experts and authorities who are trustworthy (Fricker 1998, Manor 1995).

This is obvious in the case of officially licensed indicators of scientific competence and academic expertise. Among the most important are certifications from approved educational institutions such as diplomas, degrees, credentials and testimonials, public acknowledgement of the certified qualifications by official accreditation and authorisation, membership or employment in professional institutions or in the public service. These indicators tell us not only to believe that the experts in our society are competent and able but also to believe that, provided normal conditions apply, they are acting according to appropriate extrinsic and intrinsic incentives (Baurmann 2009).

Less precise but also clearly recognisable are the more informal criteria that identify political experts and analysts as "reliable". Sometimes these will be the same criteria as in the academic case. Far more important in modern democratic societies are experts who are labelled as authorities by their membership in professional media-like television, radio or newspaper. However, that trust is conferred to them via their membership in the professional media presupposes in turn that trust is invested in these media. And at this level we can observe criteria to differentiate between respectable and dubious media in a society. The media we should trust must fulfil certain requirements to be taken seriously as a source of information - for example, an official accreditation of a newspaper or a television channel or a certain degree of coverage and circulation.

To ensure that the knowledge of political experts and analysts is made available to the public and can really contribute to the knowledge of the voters, it is necessary that a community has reliable rules and criteria to identify the trustworthy sources and authorities and that the people believe that these rules and criteria are indeed reliable and credible! Pathological distortions from a "healthy equilibrium" in this respect are possible in different directions: a society can be endowed with competent and trustworthy authorities and reliable epistemic institutions, but people do not trust them and do not believe in the validity of the social criteria that label them, and instead trust incompetent and unreliable sources: as is the case when members of a fundamentalist denomination believe in the truth of creationism which is propagated by their religious leader. Or the official 
licences of a society themselves could be corrupted — and people could be led thereby to trust incompetent or otherwise defective "authorities", for example, in authoritarian or dictatorial regimes that preach the absolute certitude of their ideology.

Therefore, the veritistic enterprise must pay attention to the conditions that promote a healthy "epistemic equilibrium". To produce and circulate the knowledge that voters should have in a democracy, we need to have efficient epistemic institutions which compile knowledge and make it available; and we need recipients who trust in these institutions and sources and believe in the reliability of the information they offer.

What conditions are conducive to a widespread trust in the "official" epistemic sources in a democracy? To answer this question one has to answer another question: namely, by what means do average citizens judge the quality of the prevailing social and institutional mechanism for identifying (political) experts and authorities in a society? How do citizens become confident that these mechanisms do serve to indicate competence, reliability and trustworthiness?

We cannot deal with these crucial questions in detail here (Goldman 2001). But whatever strategies and possibilities are, in principle, available to voters in this respect, one thing seems clear: voters will base their judgement of the trustworthiness of political experts, epistemic authorities and the professional media and of the reliability of the respective rules and criteria to identify them not only on their individual information and knowledge, but also on information and knowledge they receive from others (Baurmann 2007a). As users of the media, for example, we will often notice whether information by the media is indeed true or not and we will see differences in this respect between different kinds of newspapers or television channels. But we could hardly come to a well-founded judgement on the basis of our individual experience alone. So again we have to rely on collective knowledge.

\section{Social trust}

Political experts and the professional media are not the only sources of voters' knowledge about the performance and trustworthiness of politicians. Another important source is the personal experiences and insights of fellow citizens in regard to political issues and politicians. Moreover, the testimony of fellow citizens will be important for individuals to assess the trustworthiness of the political experts and analysts as well as the reliability of the media and other institutions of information. 
That means that the question of epistemic trust is to be raised again. If the judgement and the knowledge of fellow citizens are important for individuals, what is the basis for their trust in these sources? Again, we can uncover a number of rules which incorporate criteria for distinguishing those of our ordinary fellow citizens we should trust with regard to certain issues from those we should mistrust. These rules are highly context-dependent and cover a wide range of areas: from trivial everyday questions to religious and social subjects right up to the problem which is of interest here, namely whom should we trust as witnesses of the achievements and failures of policies and politicians, political experts and the media (Fricker 1994). The criteria specified by these rules are not specific and clear-cut. They are informal, and socially evolved. Nonetheless, they serve the function of allowing a prima facie judgement of epistemic reliability and credibility.

These rules lay the foundations for social trust and thereby-beside other things - determine the scope and nature of collective knowledge from which an individual can benefit. In this respect a continuous range of possibilities between two extremes exists (Baurmann 1997): at one extreme, epistemic trustworthiness is attributed in a highly generalized form. Rules of such a generalized social trust entail the presumption of epistemic trustworthiness as a default position: accordingly a recipient should assume that an informant conveys the truth unless there are special circumstances which defeat this presumption. Such generalized epistemic trust presupposes that relevant sources have epistemic competence in regard to the topic in question and that there are no extrinsic or intrinsic incentives to withhold the truth from others. A trivial example would be that under normal circumstances we trust that people on the street would give correct answers when asked for the time of day or for directions to a desired destination. Similarly, in our societies most people tend to believe most of the putative facts promulgated by the mass media.

The other extreme consists in attributing epistemic trustworthiness in a highly particularistic way. Individuals adhere to a particularistic trust if they trust only members of a clearly demarcated group and generally mistrust the members of all other groups. Under this condition, their epistemic sources will be restricted to people who share the distinctive features which separate them from the rest of the world and grant them membership in an exclusive group. Particularistic trust is supported by rules which are the mirror image of those rules which embody a generalized trust. Rules of generalized trust state that one should trust everybody unless exceptional 
circumstances obtain, rules which constitute particularistic trust state that one should mistrust everybody, with the exception of some specified cases. Paradigmatic examples of particularistic trust can to be found in enclosed sects, radical political parties, ostracized groups and suppressed minorities.

The availability and distribution of knowledge in a community depends critically on which form of social trust prevails. Generalized social trust in the epistemic sense enables people to utilise a huge reservoir of collective knowledge at low cost. People gain access to a large number of different sources all of which can provide them with some information and insight. In the democratic context specifically, individual voters can benefit from the experience of a huge number of other people in very diverse contexts and can base their political judgements on a broad assemblage of facts and data. In a high-trust society the individual will get a lot of information and criticism by happenstance, and on the cheap.

Particularistic trust, in contrast, has very negative consequences from an epistemic point of view. It restricts the chances of individuals to get a solid foundation for their opinion formation. The aggregated collective knowledge on which they could base their judgement of the trustworthiness of politicians and the credibility of epistemic authorities and other sources will be severely limited. But particularistic trust not only limits the available knowledge. If the collective knowledge of a particular group entails selective information and one-sided world views, the systematic lack of alternative information and views will contribute not only to unjustified mistrust of trustworthy persons and institutions, but also to an unjustified trust in untrustworthy and unreliable persons and institutions.

From a veritistic point of view, the prevalence of particularistic trust in a society is a serious threat. In politics, it limits the amount of accessible collective knowledge for individual voters and thereby restricts their chances to gather core voter knowledge, and it contains the risk that voters can adopt wrong or misleading information, which motivates them to cast their votes for untrustworthy and/or incompetent politicians. Particularistic trust is associated with the fragmentation of a society-a feature that poses a danger for democracy on a number of fronts. But epistemic considerations are to be included among the dangers.

If we ask which factors determine the scope of social trust, we are again confronted with an iteration of our problem: the rules of social trust also embody a kind of knowledge which is hardly at the disposal of one individual alone. Without the experience of others, the assessment of the 
rules of social trust would be based on thin evidence. As single individuals we cannot acquire sufficient information about the average competence of the members of our society, the incentives they face in different social contexts and situations and the motivations and attitudes they normally possess. To form a reasoned opinion about whether or not I am justified in trusting my fellow citizens, I have to know relevant facts about the institutions and the social structure of my community, the ethnic and political composition of the population, possible conflicts between the values and interests of different sub-groups and much more.

\section{Personal trust}

So far we have referred to the fact that individuals place trust in experts, institutions and their fellow citizens by applying socially shaped criteria and rules. But this does not mean that there are no situations in which people base their judgements on individual evaluation. If favourable conditions obtain in the relationship to particular persons, individuals can rely on their own knowledge and experience to assess whether these persons have competence, what kind of extrinsic incentives effect their behaviour, and what character and dispositions they reveal. We can characterize cases in which we come to trust other persons on such an "individualized" basis as instances of personal trust.

The epistemic base for this kind of personal trust lies mainly in the context of ongoing and close relationships-connections that produce a lot of information about other persons. But we can have reasoned opinions about the trustworthiness of certain persons even under less favourable conditions. Even if there is no direct relationship with a person but otherwise a regular or intensive flow of information and impressions, I may be in a position to make good guesses at the abilities, the situation and the character of the informant. Personal trust must not be reciprocal. I can deeply trust other persons without their even knowing me. I can be the ardent follower of a political or religious leader or be convinced of the trustworthiness of a famous scientist, foreign correspondent or a news moderator. This kind of "detached" personal trust can be well-founded if it is based on sufficient evidence, and even being instantly impressed by the charisma of a person is not per se misleading or irrational. We possess a certain intuitive ability to judge trustworthiness and personal integrity-at least to a certain degree (Frank 1992, Baurmann 1996, 409ff.).

The larger the number of individuals I trust personally, the broader the potential reservoir of independent information and knowledge I can 
draw from to judge the validity of social rules and criteria for the credibility and trustworthiness of people, institutions and authorities. This judgement also involves reference to testimony to a large extent - but it is testimony from sources whose quality I can evaluate myself. Therefore, I can ascribe a high "trust-value" to the testified information. In these cases my trust is based not only on predetermined rules and their more or less reliable indicators of trustworthiness but on my own, sometimes careful, individual assessment of persons and situations. Information which stems from personal confidants, therefore, often overrides the recommendations of social rules and criteria.

I will also be inclined to ascribe a comparable high trust-value to information that stems from sources whose trustworthiness has not been ascertained by myself, but by the testimony of people I personally trust. In this way it is possible to profit from a more or less widespread network of personal trust relations linked together by people who trust each other personally and thus simultaneously function as mutual trust-intermediaries (Coleman 1990, 180ff.). Such trust-networks pool information and knowledge and make that knowledge available to the individual at low costs or even for free. They represent important instances of "social capital" (Baurmann 2008).

The efficiency of personal trust-networks as information pools is enhanced if the networks transgress the borders of families, groups, communities, classes or races. The more widespread and the larger the trust networks, the more diverse and detailed the information they aggregate. Particularistic networks that only connect people of a certain category or which are very limited in their scope are constantly in danger of producing misleading, partial and one-sided information. The chances of individuals deriving from their trust-networks the quality and quantity of information they need to form a realistic and balanced picture of their world is, therefore, largely dependent on the coverage their trust-networks provide.

Trust-networks can remain latent and silent about the established social criteria for epistemic credibility and authority for a long period. The special importance of these personal trust-networks becomes evident when, for example, under a despotic regime a general mistrust towards all official information prevails. But personal trust-networks also provide fall-back resources in well-ordered societies with usually highly generalized trust in the socially certified epistemic sources (Antony 2006). Under normal circumstances in our societies we consult books, read newspapers, listen to the news and pay attention to our experts and authorities if we want to learn 
something about the world. And even when we develop mistrust towards some of those authorities or institutions, we normally do so because we hear contrary "facts" promulgated by other authorities or institutions. Nevertheless, the ultimate touchstone of my belief in testimony can only be my own judgement. And it makes an essential difference whether I can base this judgement only on my own very limited personal information or if I can rely on the information pool of a widely spread personal network which is independent of socially predetermined criteria for epistemic credibility and authority. Of course, I can myself check for internal consistency and general plausibility, and compare different kind of sources with each other-but it makes my assessment much more reliable if I can base it on the collective knowledge of a group that aggregates a huge amount of information from different areas and contexts.

We can conclude that personal trust-networks provide individuals with a pool of independent information about the trustworthiness of other people, groups, institutions, specialists, experts and politicians. Thus they improve the basis for a critical assessment of the validity of the formal and informal criteria a society develops for differentiating between reliable and unreliable sources of information and knowledge. The rules which guide and determine our social trust and our confidence in authorities and experts can be scrutinized by utilising the collective experience and knowledge which is embodied in our personal trust-networks.

Given the important function of trust-networks as ultimate sources of reliable information and testimony, a systematic restriction of their scope and an arbitrary limitation of their members has serious consequences for the quality of the collective knowledge they incorporate. Exclusive networks that only consist of people who belong to a special and limited group can create a vicious circle with social rules that prescribe particularistic social trust, whereas widespread personal networks can support and strengthen a generalized social trust and can contribute to the validity of individual knowledge. Therefore, the chances that people will get reliable information from their personal networks will be all the greater, the more these networks are open and inclusive.

\section{Summary}

The knowledge a voter should have in a democracy is preserved in different storages. It is collective knowledge that is not immediately available 
to the individual user. Therefore, the veritistic programme should not be restricted to the supply side of knowledge; it must also consider the demand side and analyse the conditions under which individual recipients will have an incentive and a chance to participate in existing collective knowledge. One important condition, as we have tried to line out, is trust in the epistemic sources.

We have referred to three kinds of epistemic sources that contribute to voter knowledge: political experts and "public explainers" as they are present mainly in the professional media, the anonymous group of fellow citizens, and members of personal networks. Each source disposes of an aggregated collective knowledge which is potentially important for individual voters. To utilise these different sorts of collective knowledge voters must place trust in the reliability of the sources: voters must trust political experts and authorities, they must believe in the reliability of the professional institutions of communication and information, they must place social trust in their fellow citizens and personal trust in the people who form their social networks.

We have pointed out that each form of trust is based on different conditions and poses different kinds of problems for verification. But most important is the phenomenon that the different forms of trust are not isolated from each other but are mutually dependent and embedded in a kind of intricate hierarchy with complicated interrelations between its different levels. Provided that a society is actually blessed with reliable institutions of public knowledge, trustworthy political experts and citizens an "optimal" veritistic situation would be one in which voters trust their institutions and experts on the basis of the given social rules and criteria, exhibit a generalized social trust and possess a widespread personal trust-network so that they can utilise collective knowledge as much as possible.

An efficient epistemic constellation can be endangered on the "demand side" - without any changes on the "supply side" — in different ways: trust in institutions and experts can weaken because people begin to question the official rules for reliability of sources - for example, if green activists challenge the expertise of scientists in regard to environment protection; generalized social trust can begin to particularize because people begin to mistrust certain groups of fellow citizens, as, for example, when the cultural homogeneity of a population dissolves; personal trust-networks can become more and more exclusive because people increasingly restrict their personal trust-for example, if new social or political conflicts arise. In all these cases the collective knowledge that will be available to a person 
will diminish—with the growing risk that that knowledge becomes biased, selective and one-sided.

Processes of trust erosion are also multilayered and interrelated. Suppose that individuals were to limit their personal trust-networks to a peculiar group of people; and that these people exhibited a particularistic social trust, and one moreover that includes only people who mistrust the offcial experts and epistemic institutions. Suppose each sub-group were to insist exclusively on the credibility of "alternative" experts. Then trust in the sources of collective knowledge might well break down in a cascade. The shape and scope of personal trust-networks will often play a crucial role in such a process.

For the veritistic agenda, therefore, lots of things matter-not only institutions but also informal social facts and processes that determine how the available knowledge of a community is adopted and accepted. In the case of democracy, it seems highly likely that voters will have access to relevant core knowledge-whatever is judged to be the specific content of that knowledge-only if there is trust in political experts and institutions which, in turn, will only prosper if that trust is embedded in a highly generalized social trust and in inclusive far-reaching personal trust-networks.

\section{BIBLIOGRAPHY}

Antony, Louise 2006: "The Socialization of Epistemology". In: Robert E. Goodin and Charles Tilly (eds.), The Oxford Handbook of Contextual Political Analysis, Oxford: Oxford University Press, 58-76.

Baurmann, Michael 1996: Der Markt der Tugend-Recht und Moral in der liberalen Gesellschaft. Tübingen: J.C.B. Mohr (Paul Siebeck). (Englisch: The Market of Virtue. Morality and Commitment in a Liberal Society, The Haguc: Springer 2002).

— 1997: "Universalisierung und Partikularisierung der Moral. Ein individualistisches Erklärungsmodell". In: Rainer Hegselmann/Hartmut Kliemt (eds.), Moral und Interesse. München: Oldenbourg, 65-110.

- 2007a: "Rational Fundamentalism? An Explanatory Model of Fundamentalist Beliefs". Episteme. Journal of Social Epistemology 4, 150-166.

- 2007b: "Markt und soziales Kapital: Making Democracy Work". Politisches Denken. Jabrbuch 2006/2007. Politik und Ökonomie, 129-155. 
Baurmann, Michael 2008: "Political Norms, Markets and Social Capital". In: Jörg Kühnelt (ed.), Political Legitimization without Morality, Wien/New York: Springer, 161-180.

- 2009: "Fundamentalism and Epistemic Authority". In: A. Aarnio (ed.), Varieties of Fundamentalism. The Tampere Club Series. Volume 3. Tampere, im Druck.

Brennan, Geoffrey and Alan Hamlin 2000: Democratic Devices and Desires. Cambridge: Cambridge University Press.

Brennan, Geoffrey and Loren Lomasky 1993. Democracy and Decision. Cambridge: Cambridge University Press.

Coady, C. A. J. 1992: Testimony, Oxford: Oxford University Press.

Coleman, James S. 1990: Foundations of Social Theory, Cambridge/London: Harvard University Press.

Fishkin, James 1991: Democracy and Deliberation: New Directions for Democratic Reform. New Haven: Yale University Press.

Frank, Robert H. (1992), Passions Within Reason. The Strategic Role of the Emotions, New York/London: W W Norton \& Co.

Fricker, Elizabeth 1994: "Against Gullibility". In: Bimal K. Matila and A. Chakrabarti (eds.), Knowing from Words. Dordrecht: Springer, 125-161.

- 1998: "Rational Authority and Social Power: Towards a Truly Social Epistemology". Proceedings of the Aristotelian Society 98, 159-177.

Goldman, Alvin I. 1999: Knowledge in a Social World, Oxford: Oxford University Press.

- 2001: “Experts: Which Ones Should You Trust?". Philosophy and Phenomenological Research LXIII, 85-110.

Govier, Trudy 1997: Social Trust and Human Communities, Montreal \& Kingston: McGill-Queen's University Press.

Hardwig, John 1991: "The Role of Trust in Knowledge". The Journal of Philosophy LXXXVIII, 693-708.

Lahno, Bernd 2002: Der Begriff des Vertrauens. Paderborn: mentis.

Leigh, Andrew and Tirta Susilo 2008: "Is Voting Skin Deep?" CEPR Research Paper RSSS ANU No. 583.

Matilal, Bimal K. and A. Chakrabarti 1994 (eds.): Knowing from Words, Dordrecht: Springer.

Manor, Ruth 1995: "My Knowledge, Our Knowledge, and Appeals to Authority". Logique \& Analyse 38, 191-207.

Schmitt, Frederick F. 1994 (ed.). Socializing Epistemology. The Social Dimensions of Knowledge, Lanham: Rowman \& Littlefield Publishers. 